\title{
Synthesis and Inhibitive Mechanism of a Novel Clay Hydration Inhibitor for Water-based Drilling Fluids
}

\author{
Weichao DU ${ }^{1,2 *}$, Xiangyun WANG $^{1}$, Taifei BI $^{3}$, Man LIU $^{4}$, Jie ZHANG $^{1}$, Gang CHEN ${ }^{1}$ \\ ${ }^{1}$ College of Chemistry and Chemical Engineering, Xi'an Shiyou University, Xi'an 710065, China \\ ${ }^{2}$ Shandong Key Laboratory of Oilfield Chemistry, China University of Petroleum (East China), Qingdao 266580, China \\ ${ }^{3}$ Oil Production No.1, Changqing Oilfield Company, Yan'an 716000, China \\ ${ }^{4}$ Oil Production No.11, Changqing Oilfield Company, Qingyang 745000, China \\ crossref http://dx.doi.org/10.5755/j02.ms.23947
}

Received 10 August 2019; accepted 02 November 2019

\begin{abstract}
In order to solve wellbore instability problem, a novel clay hydration inhibitor PDWC for water-based drilling fluids was synthesized by copolymerization of tris hydroxyethyl diallyl ammonium bromide (THDAB), sodium allyl sulfonate (AS) and methyl methacrylate (MMA) initiated by redox initiation in an aqueous solution. PDWC was characterized by Fourier transform infrared spectroscopy (FT-IR), Gel Permeation Chromatography (GPC) and Thermo-gravimetry-Differential Scanning Calorimetry (TGA-DSC), respectively. Evaluation of experiments indicated that PDWC showed superior clay hydration inhibition ability compared to some polymer and inorganic inhibitors. Characterization methods included particle size analysis, FT-IR, X-ray diffraction (XRD) and Scanning Electron Microscope (SEM) were utilized to study the inhibition mechanism of PDWC, it was observed that PDWC can be adsorbed on the surface of sodium montmorillonite (Na-MMT) by its hydroxyl functional group, which changed the micro-structure of Na-MMT and made the clay particles increased obviously. However, results of XRD demonstrated that it was difficult for PDWC to enter the inner layer crystal of Na-MMT.

Keywords: low molecular weight, clay hydration inhibitor, shale gas, water-based drilling fluids.
\end{abstract}

\section{INTRODUCTION}

A clay hydration inhibitor is a water-based of drilling fluids (WBDFs) additive that can effectively inhibit the hydration expansion of clay and maintain the stability of the wellbore [1-4]. Over the past decades, various inhibitors such as simple inorganic inhibitor, monomeric amine and its derivatives have been successfully employed to a certain degree in WBDFs, however, the temporary and low level inhibition have limited the application of them [5-7]. To overcome the performance-related shortcomings, copolymers such as hydrolyzed polyacrylamide (HPAM), hyperbranched polyglycerols, amphoteric polymer inhibitor (FA-367), PDADMAC and polyamine have been investigated [8]. Among the existing inhibitors, large molecular weight copolymer can be wrapped in the surface of clay and formed a coating film to effectively prevent drilling instability. However, high molecular weight copolymers show the great influence on the rheological properties of WBDFs as well as the high molecular weight copolymer chains are easily curled and failed in the highsalt and high-calcium environment $[9,10]$.

Some works have proved that low molecular weight polymer showed excellent salt and temperature resistance ability in WBDFs, and low molecular weight polymers such as polyamine, hyperbranched polymer has greatly aroused the interest of oilfield researchers in shale drill operations in the last years [11]. Zwitterionic polymer own both an anionic and a cationic group, and shows great advantages in WBDFs. Zhao [12] has synthesized a zwitterionic polymer
AM/DMC/AMPS as a low-molecular-weight encapsulator in deep-water drilling fluids and showed strong clay inhibition ability. However, there are still few reports about low molecular weight of zwitterionic polymers as shale inhibitor so far. In the present paper, AS and MMA were copolymerized with a novel cationic monomer THDAB to synthesize a low molecular weight of zwitterionic copolymer and clay hydration inhibitor PDWC for WBDFs. Where THDAB acts as a functional monomer which ensure the strong adsorption of PDWC onto clay surface by reacting with the silanol groups and negative charges on the clay, MMA acts as a hydrophobic monomer which can hydrophobize the clay surface and to isolate clay form water; AS acts as a hydration monomer to ensure of copolymer with outstanding salt and temperature resistance performance. The copolymer was characterized by FTIR spectroscopy in the mid-infrared region (MIR), Gel Permeation Chromotography (GPC) and Thermogravitometry Differentiac Scanning Calorimetry (TGADSC). Roll recovery and linear expansion experiments was used to its study inhibition performance. The inhibition mechanism of PDWC was discussed in detail via particle size analysis, also by FTIR, XRD and SEM in this paper.

\section{EXPERIMENTAL}

\subsection{Materials}

AS, MMA, trolamine, allyl bromide, $\left(\mathrm{NH}_{4}\right)_{2} \mathrm{~S}_{2} \mathrm{O}_{8}$, $\mathrm{NaHSO}_{3}$, ethanol, ethyl acetate and isopropanol were all of

\footnotetext{
* Corresponding author. Tel.: +86-15829920510
}

E-mail address: duweichao@xsyu.edu.cn (W.C. Du) 
analytical pure and purchased from Kelon Co., Ltd, Chengdu, China. Poly-ECH-DMA with molecular weight 32352 g/mol was supplied by Maikeba Mud Co., Ltd, USA. PF-CMJ with molecular weight $2.3 \times 10^{5} \mathrm{~g} / \mathrm{mol}$ and amphoteric polymer inhibitor XY-27 with $4362 \mathrm{~g} / \mathrm{mol}$ was received from Engineering Technology Research Institute Co., Ltd., CNPC, Beijing, China. PAM with molecular weight $1.8 \times 10^{5} \mathrm{~g} / \mathrm{mol}$ and FA-367 with molecular weight $1.2 \times 10^{4} \mathrm{~g} / \mathrm{mol}$ were supplied by Sichuan Guangya polymer technology Co., Ltd, Chengdu, China. Na-montmorillonite with cation exchange capacity of $81 \mathrm{meq} / 100 \mathrm{~g}$ $(0.81 \mathrm{mmol} / \mathrm{g})$ was obtained from Xia Zijie Bentonite Technology Co., Ltd, Xinjiang, China. The shale sample was obtained from Longmaxi shale gas field, Chongqing, China, and the mineral compositions of shale sample is illustrated in Table 1.

Table 1. Mineral compositions of shale samples

\begin{tabular}{|c|c|c|c|c|c|}
\hline \multirow{2}{*}{$\begin{array}{c}\text { Shale } \\
\text { samples }\end{array}$} & \multicolumn{4}{|c|}{ mineral compositions, \% } & \multirow{2}{*}{ I/S } \\
\cline { 2 - 5 } & $\mathrm{K}$ & $\mathrm{Ch}$ & $\mathrm{I}$ & $\mathrm{I} / \mathrm{S}$ & \\
\cline { 2 - 6 } & 0.00 & 26.30 & 65.05 & 8.65 & 10.00 \\
\hline
\end{tabular}

\subsection{Synthesis of polymeric monomer THDAB}

THDAB was prepared based on a method previously reported [13, 14], as shown in Fig. 1 . Trolamine $(0.20 \mathrm{~mol})$, allyl bromide $(0.20 \mathrm{~mol})$, and ethanol $(150 \mathrm{~mL})$ were placed in a round-bottom flask equipped with a reflux condenser and refluxed for $24 \mathrm{~h}$ with magnetic stirring at temperature $50{ }^{\circ} \mathrm{C}$. After cooling to room temperature $\left(21^{\circ} \mathrm{C}\right)$ the solution was concentrated under reduced pressure and redissolved in ethyl acetate and ethanol (ethyl acetate: ethanol $=7: 3$ ). Product was isolated in high yield as a rodlike crystals or white powder after placed in room temperature for $24 \mathrm{~h}$. Yield: $94.3 \%$. ${ }^{1} \mathrm{H}$ NMR (400 MHz, $\left.\mathrm{D}_{2} \mathrm{O}\right): 5.62-5.75(\mathrm{~m}, 1 \mathrm{H}, \mathrm{CH}=\mathrm{C}), 4.89 \sim 5.07(\mathrm{~m}, 2 \mathrm{H}, \mathrm{C}=$ $\mathrm{CH}_{2}$ ), 3.75 3.76 (d, 6H, $\left.\mathrm{CH}_{2}-\mathrm{O}\right), 3.60$ (t, $2 \mathrm{H},-\mathrm{CH}-\mathrm{C}=\mathrm{C}$ ), 3.33 (t, 3H, -OH), 3.04 3.06(t, 6H, N-CH $-\mathrm{C}-\mathrm{OH})$; FT-IR $(\mathrm{KBr}), / \mathrm{cm}^{-1}$ : 3360, 2920, 1630, 1400, 1080, 1010, 900, 520.

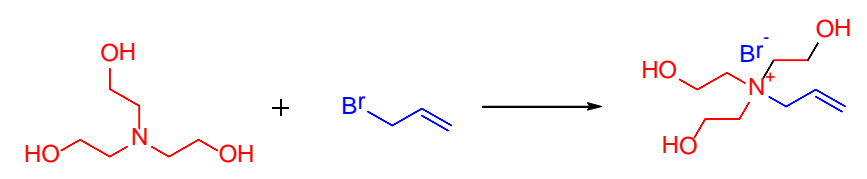

Fig. 1. Synthesis route of THDAB

\subsection{Synthesis of PDWC}

PDWC was synthesized by redox free radical copolymerization in aqueous solution, the synthesis of PDWC is shown in Fig. 2. Concerned amounts of AS (4 g) was dissolved in deionized water $(10 \mathrm{ml})$, the $\mathrm{pH}$ was adjusted to the indicated value at 7.0 by using $30 \mathrm{wt} . \%$ $\mathrm{NaOH}$ solutions. Subsequently, 2 g MMA and $4 \mathrm{~g}$ THDAB were added to flask with stirring at constant temperature under nitrogen atmosphere for $10 \mathrm{~min}$. Further, the initiator $\mathrm{K}_{2} \mathrm{~S}_{2} \mathrm{O}_{8}(0.1 \mathrm{~g})$ and $\mathrm{NaHSO}_{3}(0.1 \mathrm{~g})$ was added. The polymerization was proceeded out at $70{ }^{\circ} \mathrm{C}$ for $1 \mathrm{~h}$ while constant stirring, and then was added isopropanol to the solution, polymerization was preceded at $70^{\circ} \mathrm{C}$ for another $5 \mathrm{~h}$. The resulting product was obtained by repeatedly washing with ethanol to remove monomers, isopropanol and initiator. Then, PDWC was further dried under vacuum oven at temperature $65^{\circ} \mathrm{C}$ for $24 \mathrm{~h}$ with the yield $79.3 \%$.

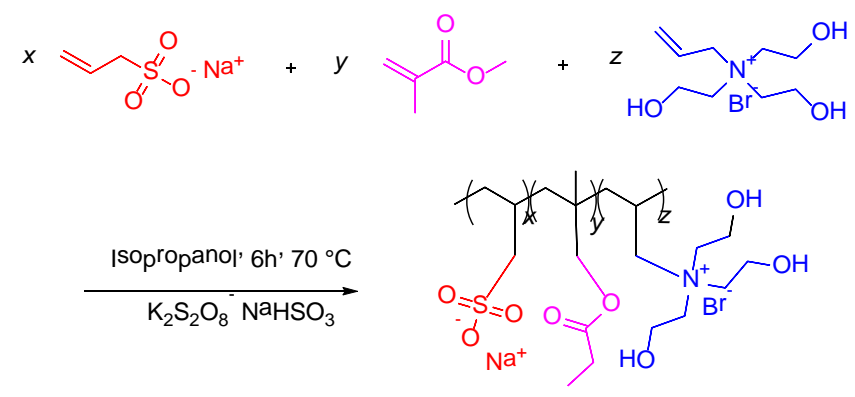

Fig. 2. Synthesis of PDWC

\subsection{Characterization}

The infrared spectra were collected using the WQF-520 fourier transform infrared spectrometer. The IR source, $\mathrm{KBr}$ beam splitter and DTGS detector was used for the mid-IR measurements $\left(4000-400 \mathrm{~cm}^{-1}\right)$. ${ }^{1} \mathrm{H}$ NMR spectra was carried out by using a Bruker AV-400 nuclear magnetic resonance spectrometer with chemical shift values in ppm downfield from TMS using $\mathrm{D}_{2} \mathrm{O}$ as solvents. GPC was utilized to measure the molecular weight distributions by using an Alliance e2695 instrument (Waters, USA). The measurement conditions were as follows: trichlorobenzene was used as the mobile phase, the flow rate was $1 \mathrm{ml} / \mathrm{min}$, column temperature was $150^{\circ} \mathrm{C}$, injection volume and operation hours were $50 \mu \mathrm{L}$ and $90 \mathrm{~min}$, respectively. TGADSC measurements were acquired on a simultaneous TGADSC (METTLER TOLEDO, Swiss) instrument under nitrogen atmosphere flow $\left(40 \mathrm{~mL} \mathrm{~min}^{-1}\right)$ with the heating rate of $10^{\circ} \mathrm{C} \mathrm{min}^{-1}$.

\subsection{Inhibition performance evaluation}

\subsubsection{Linear swelling measurements}

Linear swelling measurements were carried out in laboratory by using CPZ-2 swelling instrument (Dongying, China). The artificial core was made by using $10 \pm 0.01 \mathrm{~g}, 40$ mesh Na-MMT powder, which was pressed tightly into a sample tube via hydraulic compactor under $10 \mathrm{MPa}$ for 5 min. The linear swelling rates over the whole experimental time at atmospheric pressure condition were obtained by using the following

$V_{H}=\frac{R_{t}}{H} \times 100 \%$,

where $V_{H}$ is the swelling ratio of artificial core; $R_{t}$ is the change in length of artificial core, $\mathrm{mm} ; H$ is the original length of artificial core.

\subsubsection{Hot-rolling recovery tests}

The shale cutting samples used in this section were obtained from Longmaxi shale gas field, and the tests were conducted at $100 \mathrm{C}$ for $16 \mathrm{~h}$.

\subsection{Inhibition mechanism study}

3 g PDWC was added into $100 \mathrm{~mL}$ WBDFs and stirred for $2 \mathrm{~h}$, subsequently centrifuged for $30 \mathrm{~min}$ and collected the precipitation. The precipitate was dried in a vacuum oven to constant weight at $100^{\circ} \mathrm{C}$ for $24 \mathrm{~h}$, and then 
measured via a WQF-520 by Fourier transform infrared spectrometer.

Inhibitor with certain concentrations was added into WBDFs and stirred for $2 \mathrm{~h}$. Subsequently, particle size analysis was measured with a laser diffraction technique (HORIBA, Japan).

Samples were prepared as described in "FT-IR analysis"' section, both the dry and wet precipitations were performed. XRD data were collected X Pert PRO MPD diffract meter in the range $3-30^{\circ}(2 \theta)$ with a step size of $0.02^{\circ} 2 \theta$ and a nominal scan rate of 3 s per step and at room temperature.

SEM analysis performed investigated with a FEI Quanta 450 instrument, range of the magnifying multiple was from 500 to 5000, the samples were trimmed from the bottom of the API filter cake, and images were carried out at $120-500 \mathrm{~Pa}$.

\section{RESULTS AND DISCUSSION}

\subsection{Characterizations of PDWC}

\subsubsection{FT-IR characterization}

Fig. 3 shows the FT-IR spectra of THDAB, MMA, AS and copolymer PDWC.

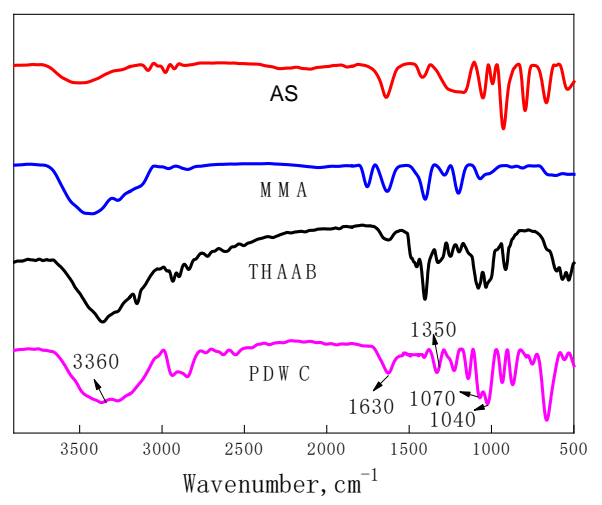

Fig. 3. FT-IR spectra of AS, MMA, THDAB and PDWC

For PDWC, the peak at $3360 \mathrm{~cm}^{-1}$ was due to the $-\mathrm{OH}$ stretching band of THDAB, the recorded strong peak wit maximum at $1630 \mathrm{~cm}^{-1}$ was assigned to the stretching vibration $\mathrm{C}=\mathrm{O}$, the peaks at approximate $1070 \mathrm{~cm}^{-1}$ and $1040 \mathrm{~cm}^{-1}$ was assigned to the $-\mathrm{SO}_{3} \mathrm{H}$ stretching vibration, indicated AS was involved in the copolymerization. Absorbtion bands at $1350 \mathrm{~cm}^{-1}$ and $1066 \mathrm{~cm}^{-1}$ were attributed to the characteristic absorption peak of $\mathrm{C}-\mathrm{N}$ and C-O-C, respectively [15]. The FT-IR results demonstrated that PDWC contains characteristic functional groups absorption peaks of each monomer, indicating that AS, THDAB and MMA were successful copolymerized to the target product PDWC.

\subsubsection{Molecular weight measurement}

Because of reduce the impact of random errors on the measurement results, molecular weight was measured under the three parallel experiment conditions, and the results are shown in Fig. 4 and Table 2.

From Fig. 4 and Table 2 we can conclude that PDWC has a certain width of molecular weight distribution and the average $M w$ of PDWC was $21540 \mathrm{~g} / \mathrm{mol}$. With a wide molecular weight distribution, the low molecular weight of PDWC $(800-5000 \mathrm{~g} / \mathrm{mol})$ could inter the layer of tetrahedral crystal compress the diffusion electric double layer of shale [16], and the large molecular weight part could be packed on the surface of the clay to prevent hydration dispersion of clay.

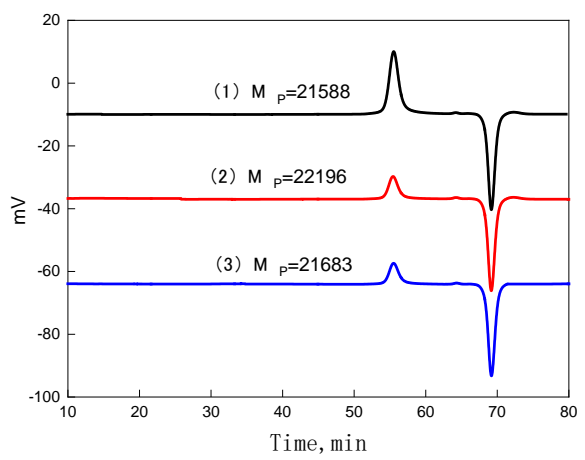

Fig. 4. Molecular weight distribution of PDWC: (1)-the first measurement result; (2)-the second measurement result; (3) - the third measurement result

Table 2. Molecular weight distribution datas of PDWC

\begin{tabular}{|c|c|c|c|c|c|c|}
\hline & Mn & Mw & Mp & $\mathrm{M}_{\mathrm{z}}$ & $\mathrm{M}_{\mathrm{z}}+1$ & Polydispersity \\
\hline $1^{\text {th }}$ & 18851 & 21307 & 21588 & 23396 & 25894 & 1.130288 \\
\hline $2^{\text {th }}$ & 19978 & 21899 & 22196 & 23632 & 25576 & 1.096131 \\
\hline $3^{\text {th }}$ & 19585 & 21416 & 21683 & 23138 & 25149 & 1.093492 \\
\hline
\end{tabular}

\subsubsection{TGA-DSC measurement}

TGA-DSC analysis was utilized to investigate the thermal stability of the pure dried PDWC, and the thermal gravimetric curve displayed four stages for the weight loss, which are shown in Fig. 5.

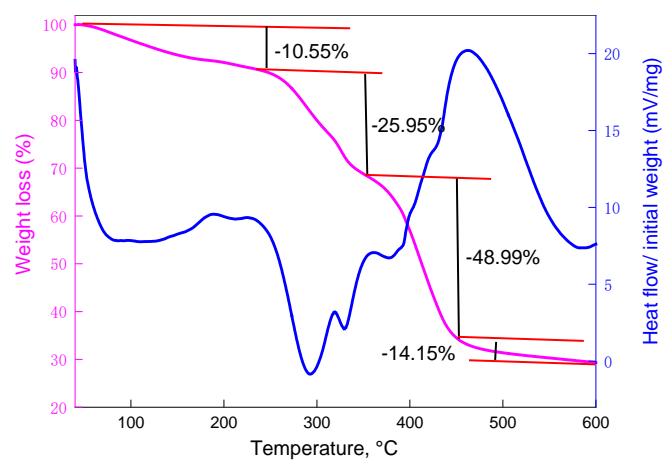

Fig. 5. TGA-DSC curves of PDWC

As shown in Fig. 5, the first stage with a mass loss of 10.55 mass \% in the temperature range $40-246{ }^{\circ} \mathrm{C}$ was due to the evaporation moisture of the intramolecular and intermolecular, which has combined with oxygen, sulfur atom, amide groups of PDWC. The second degree took place in the temperature range $246-352{ }^{\circ} \mathrm{C}$ with a loss of mass $25.95 \%$ was probably mainly due to the decompositions of amide and quaternary ammonium groups. The third decomposition one occurred in the $352-446^{\circ} \mathrm{C}$ temperature range with a prodigious loss of 48.99 mass \% mainly ascribed to the decomposition of PDWC, which due to the degradation of $\mathrm{C}-\mathrm{C}$ in the main chain [15]. The final step in the temperature range $446-600^{\circ} \mathrm{C}$ showed the main structure of PDWC was 
mostly destroyed. From the DSC curve has been identified obvious heat absorption at $288^{\circ} \mathrm{C}$, which could be attributed to the initial extensive decomposition of PDWC. The combined results of TGA and DSC demonstrated that PDWC possesses excellent thermal stability. Therefore, PDWC has a potential application in high temperature and pressure (HTHP) well.

\subsection{Inhibition property evaluation}

The hot-rolling recovery and linear swelling tests were carried out study the inhibition performance of PDWC, the results are shown in Table 3 and Table 4.

Table 3. Inhibition performance of PDWC aqueous solutions

\begin{tabular}{|c|c|c|c|c|c|c|}
\hline wt.\% & $\begin{array}{c}\mathrm{AV}, \\
\mathrm{mPa} \cdot \mathrm{s}\end{array}$ & $\begin{array}{c}\mathrm{PV}, \\
\mathrm{mPa} \cdot \mathrm{s}\end{array}$ & $\begin{array}{c}\text { YP, } \\
\mathrm{Pa}\end{array}$ & $\Phi 6 / \Phi 3$ & $\begin{array}{c}\text { Swelling } \\
\text { hight, mm }\end{array}$ & $\begin{array}{c}\text { Rolling } \\
\text { recovery,\%* }\end{array}$ \\
\hline 0.5 & 4 & 3 & 1 & $1 / 1$ & 13.6 & 58.6 \\
\hline 1.0 & 5.5 & 4 & 1.5 & $1 / 1$ & 11.3 & 73.3 \\
\hline 1.5 & 6 & 4 & 2 & $1 / 1$ & 8.1 & 80.6 \\
\hline 2.0 & 7.5 & 6 & 1.5 & $1 / 1$ & 6.7 & 91.6 \\
\hline 2.5 & 11 & 8 & 3 & $2 / 1$ & 6.1 & 93.3 \\
\hline 3.0 & 14.5 & 10 & 4.5 & $2 / 1$ & 5.9 & 94.2 \\
\hline
\end{tabular}

Table 3 shows the effect of amount of inhibitor on its solution viscosity and inhibition properties. As the amount of PDWC increased, the aqueous solution viscosity increased as well as the inhibition ability too increased. When the addition amount was $2.0 \mathrm{wt}, \%$, also the linear expansion height of Na-MMT at normal temperature and normal pressure and the rolling recovery of drill cuttings were $6.7 \mathrm{~mm}$ and $91.6 \%$, respectively. Therefore, the optimum amount of PDWC in water was $2.0 \mathrm{wt} \%$.

The inhibition properties of PDWC and other inhibitors were compared in this paper, as shown in Table 4.

Table 4. Inhibition performance of several inhibitor

\begin{tabular}{|l|c|c|}
\hline \multicolumn{1}{|c|}{ Inhibitor } & $\begin{array}{c}\text { Rolling recovery } \\
\text { ratem, \% }\end{array}$ & $\begin{array}{c}\text { Swelling hight, } \\
\text { mm }\end{array}$ \\
\hline 2.0 wt.\% PDWC & 91.6 & 6.70 \\
\hline 0.5 wt.\% XY-27 & 56.8 & 9.72 \\
\hline 0.5 wt.\% FA-367 & 82.6 & 4.98 \\
\hline $\begin{array}{l}2.0 \text { wt.\% Poly- } \\
\text { ECH-DMA }\end{array}$ & 79.2 & 9.91 \\
\hline 0.5 wt.\% PAM & 62.3 & 5.71 \\
\hline 2.0 wt.\%PF-CMJ & 72.6 & 7.12 \\
\hline ※olling condition: $100{ }^{\circ} \mathrm{C} \times 16 \mathrm{~h}$. \\
\hline
\end{tabular}

As shown in Table 4, as a low molecule zwitterionic inhibitor, XY-27 showed limited inhibition and its rolling recovery was only $56.8 \%$. The coating agent FA-367 demonstrated high clay hydration dispersion performance and its rolling recovery rate was up to $82.6 \%$. Poly-ECHDMA can adsorb on the clay surface with there are large amount of adsorbable group hydroxyl groups in it, and own a high clay hydration inhibition ability. As a film-forming plugging agent, $\mathrm{PF}-\mathrm{CMJ}$ can be firmly adsorbed on the surface of clay to provide excellent clay hydration inhibition effect. From the results it is possible conclude that for all cases, the polymer inhibitors evaluated in this work all shows superior clay hydration dispersion inhibition performance.

\subsection{Inhibition mechanism analysis}

\subsubsection{FT-IR analysis}

FT-IR spectroscopy is a very sensitive and suitable technique to probe the interaction type, configuration and local environment of the Na-MMT modified by intercalating agent. The adsorption of PDWC on Na-MMT has been confirmed by FT-IR spectra in this paper.

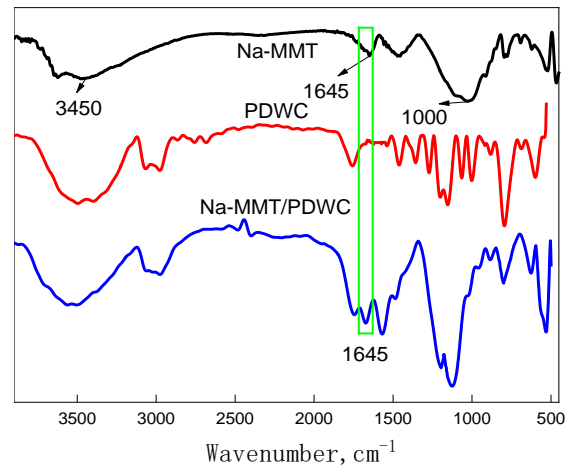

Fig. 6. FT-IR spectra of Na-MMT, PDWC and Na-MMT/PDWC

As shown in Fig. 6, in the infrared spectrum of pure NaMMT, the peak at $3450 \mathrm{~cm}^{-1}$ is due to the bending vibration band of Al-O-H, and the absorption band at $1645 \mathrm{~cm}^{-1}$ correspond to the bending vibrations of water molecules present in the montmorillonite. A strong complex band at $1037 \mathrm{~cm}^{-1}$ is attributed to the stretching vibration of $\mathrm{SiO}$ groups of the tetrahedral sheets [17-19]. Some peaks belong to PDWC such as $3360 \mathrm{~cm}^{-1}, 3159 \mathrm{~cm}^{-1}, 1630 \mathrm{~cm}^{-1}$, $1350 \mathrm{~cm}^{-1}$ and $1070 \mathrm{~cm}^{-1}$, are observed in the spectrum of Na-MMT/PDWC composite material, indicating the successful modification of Na-MMT with PDWC. Adsorption bands at $1645 \mathrm{~cm}^{-1}$ corresponding to the water was weaker when compared to the pure Na-MMT, showing the significant decrease of adsorbed water in Na-MMT, indicating an increase in the hydrophobicity of the modified sample. This is phenomenon is similar to that reported in the literature [17-22]. Decreased intensity was observed near vibration band of Si-O at $1000 \mathrm{~cm}^{-1}$ in Na-MMT, indicating that PDWC could react with Si-O of Na-MMT.

\subsubsection{Particle distribution tests}

It is well known that flocculation will be happen when positive polymer is added to the drilling fluids. The inhibition mechanism was further evaluated by particle distribution tests, and the results are shown in Fig. 7 and Table 5.

As shown in Fig. 7 and Table 5, for the case in distilled water, Na-MMT illustrated tiny particle size at $33.06 \mu \mathrm{m}$. In this paper was observed particle size of Na-MMT has been increased to $366.00 \mu \mathrm{m}, 435.76 \mu \mathrm{m}$ and $398.75 \mu \mathrm{m}$ in 1.5 wt.\%, 2.0 wt. $\%$ and 2.5 wt.\% PDWC solutions, respectively. As the amount of PDWC increased, the particle size of Na-MMT was increasing. However, when the addition amount exceeds $2.0 \mathrm{wt}$.\%, we observed that the particle size has decreased, the reason may be that the adsorption of polymer on the clay surface has reached saturation, and the agglomerated clay particles have been reseparated, which resulting in particle size decreased. 

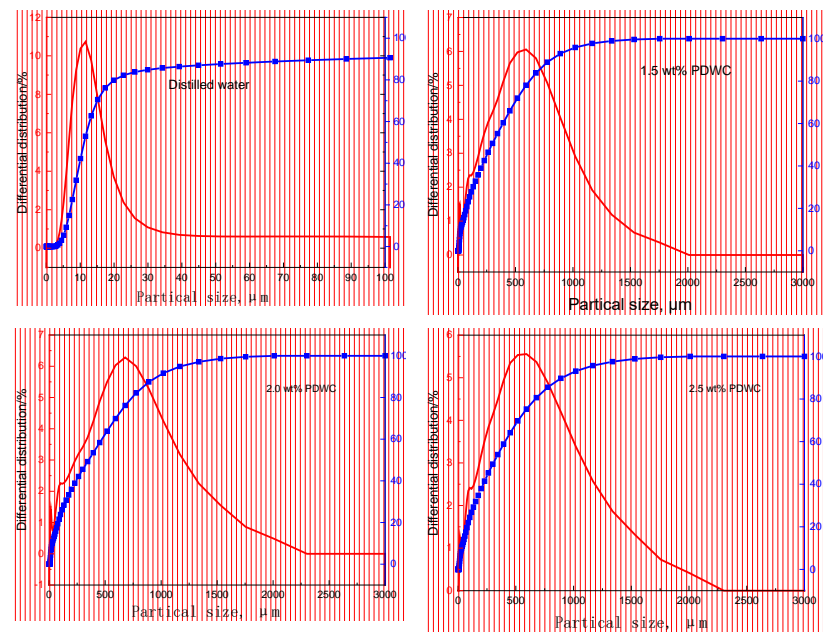

Fig. 7. Effect of PDWC on the particle size dispersion of Na-MMT

Table 5. Effect of PDWC on the particle size dispersion of Na-MMT

\begin{tabular}{|c|c|c|c|c|c|}
\hline $\begin{array}{c}\text { Add } \\
\text { amount, } \\
\text { wt.\% }\end{array}$ & $D_{10, \mu \mathrm{m}}$ & $D_{50, \mu \mathrm{m}}$ & $D_{90, \mu \mathrm{m}}$ & $\begin{array}{c}\text { Medium } \\
\text { diameter, } \\
\mu \mathrm{m}\end{array}$ & $\begin{array}{c}\text { Average, } \\
\mu \mathrm{m}\end{array}$ \\
\hline 0.0 & 5.97 & 11.14 & 87.7 & 11.14 & 33.06 \\
\hline 1.5 & 21.92 & 294.24 & 806.15 & 294.24 & 366.00 \\
\hline 2.0 & 25.68 & 352.72 & 965.95 & 352.72 & 435.76 \\
\hline 2.5 & 29.86 & 305.86 & 899.93 & 305.86 & 398.75 \\
\hline
\end{tabular}

\subsubsection{XRD analysis}

It is well known that clay crystal layers, mainly value of basal spacing $d_{(001)}$, are affected by water molecules, cationic compounds, adsorbents, intercalating agents, etc [23]. The effects of PDWC on Na-MMT interlayer spacing are shown in Fig. 8.
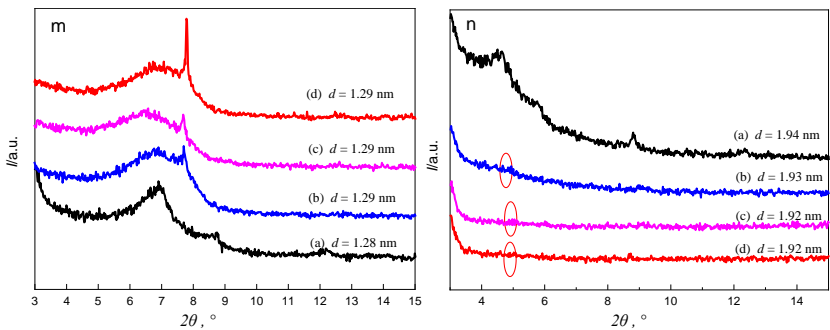

Fig. 8. X-ray diffraction patterns of modified Na-MMT (m), dry samples and (n), wet samples. (a)-pure Na-MMT;

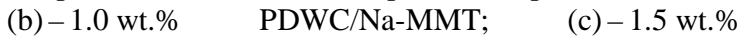
PDWC/Na-MMT; (d) - 2.0 wt.\% PDWC/Na-MMT

Fig. 8 shows the dry and wet X-ray diffraction patterns for the basal spacing $d_{(001)}$ diffraction peaks of Na-MMT and Na-MMT/PDWC. As displayed in (Fig. $8 \mathrm{~m}$ ), it can be seen that the interlayer spacing of dry Na-MMT is $1.28 \mathrm{~nm}$, and that of Na-MMT treated with 1.0 wt.\%, $1.0 \mathrm{wt} . \%$ and $2.0 \mathrm{wt} . \%$ remained almost the same and that $1.29 \mathrm{~nm}$. There was only a slight changed in the interlayer distance of the dry Na-MMT when treated by PDWC, indicating that it was difficult for PDWC to enter the interlayer spacing. For the wet case (Fig. $8 \mathrm{n}$ ), due to the hydration expansion of NaMMT, the spacing distance of wet clay has increased from 1.28 to $1.94 \mathrm{~nm}$ compared with that of dry clay, indicating that in the interlayer was sodium ion [24]. After treatment by PDWC, it was found that the interlaminar spacing decreased slightly. The results showed that it is difficult for PDWC enter the inter layer.

\subsubsection{SEM observations}

SEM is a convenient technology to observe the morphological changes of Na-MMT composites. The obtained SEM images are demonstrated in Fig. 9.
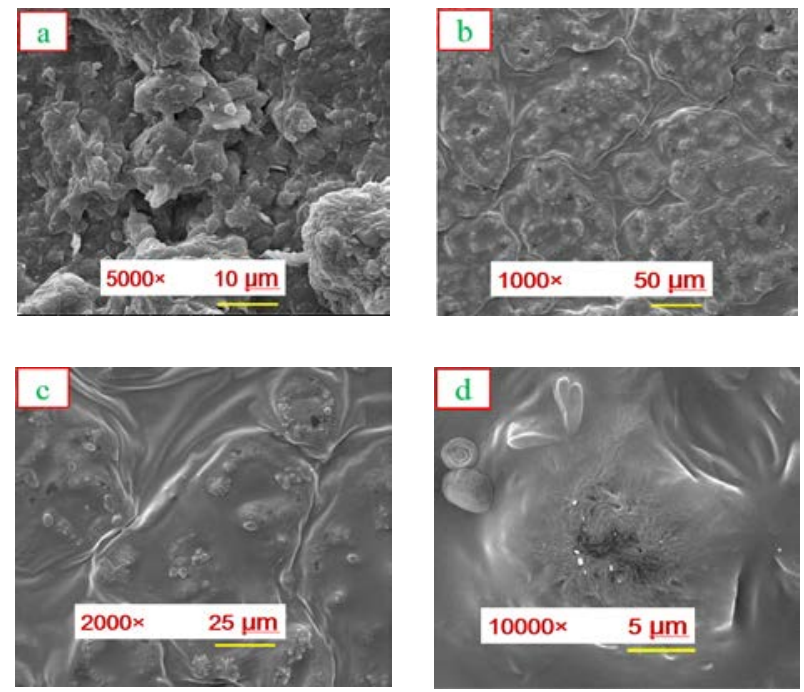

Fig. 9. SEM images of modified Na-MMT: a -basic muds cake; b, c, d-treated with 2 wt.\% PDWC

During the preparation process of samples, there was applied light pressure $(0.69 \mathrm{MPa})$ on the surface of mud cake. Compared with the four images, without PDWC, there are large holes in the mud cake, indicating the poor bonding force between of Na-MMT particles. In contrast, after treated by 2 wt.\% PDWC, there was a thin polymer film on the surface of the cake, which indicating PDWC can inhibit the clay dispersion by wrapping in the clay surface. In Fig. 9 d, SEM observation showed that there was a "silklike" vein on the cake, this structure might be a composite material after the interaction of PDWC on Na-MMT.

Through the inhibition property evaluation of PDWC by a range of methods, and reference to swelling inhibition mechanism analysis reported by other work, we have proposed the inhibition mechanism of PDWC for inhibition clay hydration, as shown in Fig. 10.

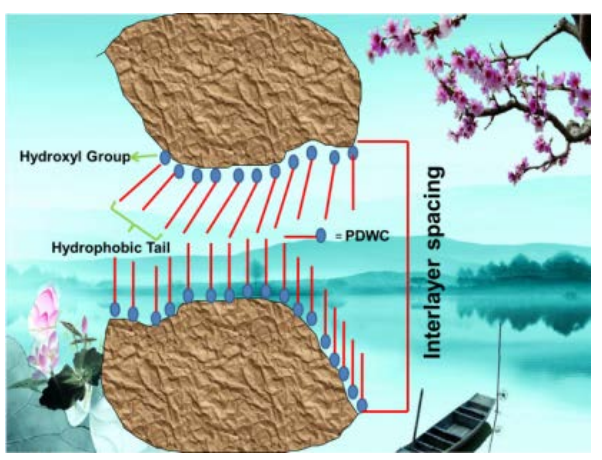

Fig. 10. Inhibition mechanism analysis of PDWC on clay hydration

Owing to the fact that hydroxyl and quaternary ammonium functional groups and the low molecular weight of PDWC, the polymer can adsorb onto clay , which would 
lead to the collapse of the diffuse double layer and further result the sedimentation occurs [25]. In addition, the hydrophobic ester group of the polymer molecule can increase hydrophobicity to the hydrophilic clay surface, which is conducive to clay repelling water molecules. In the hot-rolling recovery tests, we found that PDWC showed excellent hydration inhibition property. A possible explanation to the phenomenon might be that the larger molecular weight part of PDWC can be wrapped on clay surface to prevent hydration and dispersion caused by the hydration of clay. What's more, dispersion was not easy to occur while clay particles could be fixed on the long chain of PDWC.

\section{CONCLUSIONS}

In conclusion, a clay hydration inhibitor PDWC for water-based drilling fluids was successfully prepared from THDAB, AS and MMA. The copolymer was characterized by FT-IR spectroscopy, GPC and TGA-DSC analysis. Results demonstrated that molecular weight of PDWC was $21540 \mathrm{~g} / \mathrm{mol}$ and its temperature resistance ability was up to $288^{\circ} \mathrm{C}$. Regarding the inhibition performance, evaluation experiments showed the hot rolling recovery rate of longmaxi shale cutting sample in 2.0 wt.\% PDWC solutions was up to $91.6 \%$ after hot rolling for $16 \mathrm{~h}$ at $100{ }^{\circ} \mathrm{C}$. Linear expansion height of shale in $2.0 \mathrm{wt}$ \% PDWC solution was just $6.7 \mathrm{~mm}$ after $16 \mathrm{~h}$, performance evaluation experiments indicated that PDWC possessed superior inhibition properties compared to some polymer and inorganic inhibitors. The strong adsorption of PDWC on clay could be guaranteed by the hydroxyl, amine and mono-quaternary amine functionality groups in PDWC. In summary, the superior performance makes this new clay hydration inhibitor a promising candidate in water-based drilling fluids.

\section{Acknowledgements}

The authors would like to thank "the Opening Fund of Shandong Key Laboratory of Oilfield Chemistry", "the Fundamental Research Funds for the Central Universities (19CX05006A)" and "Natural Science Basic Research Program of Shaanxi (Program No. 2020JQ-785)“ for financial support.

\section{REFERENCES}

1. Vryzas, Z., Kelessidis, V.C. Nano-Based Drilling Fluids: A Review Energies 10 (4) 2017: pp. 540-574. https://doi.org/10.3390/en10040540.

2. Chen, S.Y., Shi, Y.P., Yang, X.Y., Xie, K.Z., Cai, J.H. Design and Evaluation of a Surfactant-Mixed Metal Hydroxide-Based Drilling Fluid for Maintaining Wellbore Stability in Coal Measure Strata Energies 12 (10) 2019: pp. $1862-1881$. https://doi.org/10.3390/en12101862.

3. Wilson, M.J., Wilson, L. Clay Mineralogy and Shale Instability: An Alternative Conceptual Analysis Clay Minerals 49 (2) 2014: pp. 127-145. https://doi.org/10.1180/claymin.2014.049.2.01.

4. Anderson, R.L., $\quad$ Ratcliffe, I., $\quad$ Greenwell, H.C., Williams, P.A., Cliffe, S, Coveney, P.V. Clay Swelling-A
Challenge in the Oilfield Earth-science Reviews 98 (3-4) 2010: pp. $201-216$.

https://doi.org/10.1016/j.earscirev.2009.11.003.

5. Gholami, R., Elochukwu, H., Fakhari, N. Sarmadivaleh, M. A Review on Borehole Instability in Active Shale Formations: Interactions, Mechanisms and Inhibitors Earth-science Reviews 177 2018: pp. 2-13. https://doi.org/10.1016/j.earscirev.2017.11.002.

6. Ni, X.X., Jiang, G.C., Li, Y.Y., Yang, L.L., Li, W.Q., Wang, K., Deng, Z.Q. Synthesis of Superhydrophobic Nanofluids as Shale Inhibitor and Study of the Inhibition Mechanism Applied Surface Science 484 2019: pp. 957-965. https://doi.org/10.1016/j.apsusc.2019.04.167.

7. Rana, A., Arfaj, M.K., Saleh, T.A. Advanced Developments in Shale Inhibitors for Oil Production with Low Environmental Footprints-A Review Fuel 2472019 : pp. 237 - 249. https://doi.org/10.1016/j.fuel.2019.03.006.

8. Ahmed, H.M., Kamal, M.S., Al-Harthi, M. Polymeric and Low Molecular Weight Shale Inhibitors: A Review Fuel 251 2019: pp. 187-217. https://doi.org/10.1016/j.fuel.2019.04.038.

9. Gou, S.H., Yin, T., Liu, K., Guo, Q.P. Water-Soluble Complexes of an Acrylamide Copolymer and Ionic Liquids for Inhibiting Shale Hydration New Journal of Chemistry 39 (3) 2015: pp. 2155-2161. https://doi.org/10.1039/C4NJ01741B.

10. Liu, X.J., Liu, K., Gou, S.H., Liang, L.X., Luo, C., Guo, Q.P. Water-Soluble Acrylamide Sulfonate Copolymer for Inhibiting Shale Hydration Industrial \& Engineering Chemistry Research 53 (8) 2014: pp. 2903-2910. https://doi.org/10.1021/ie403956d.

11. Jia, H., Huang, P., Wang, Q.X., Han, Y.G., Wang, S.Y., Zhang, F., Pan, W., Lv, K.H. Investigation of Inhibition Mechanism of Three Deep Eutectic Solvents as Potential Shale Inhibitors in Water-Based Drilling Fluids Fuel 244 2019: pp. 403-411. https://doi.org/10.1016/j.fuel.2019.02.018.

12. Zhao, X., Qiu, Z.S., Zhang Y.J., Zhong, H.Y., Huang, W.A., Tang, Z.C. Zwitterionic Polymer P(AMDMC-AMPS) as a Low-Molecular-Weight Encapsulator in Deepwater Drilling Fluid Apply Science 7 (6) 2017: pp. 594-810. https://doi.org/10.3390/app7060594.

13. Pu, X.L., Du, W.C., Sun, J.S., Luo, X., Zhang, H.D. Synthesis and Application of a Novel Polyhydroxy Amine Clay Anti-Swelling Agent Petrochemical Technology 45 2016: pp. 595-600. http://www.shiyouhuagong.com.cn/CN/Y2016/V45/I5/595.

14. Silva, F., Siopa, F., Figueiredo, B., Gonçalves, A., Pereira, J.L., Gonçalves, F., Coutinho, J., Afonso, C., Ventura, S. Sustainable Design for Environment-Friendly Monoand Dicationic Cholinium-Based Ionic Liquids Ecotoxicology and Environmental Safety 108 2014: pp. $302-310$. https://doi.org/10.1016/j.ecoenv.2014.07.003.

15. Chen, G.H., Li, I.Z., Zhu, Z.Y., OUYANG, J., Wang, F., Wang, Y.Y., Xue, J.J. Synthesis of Ultra High Molecular Weight HPAM and Viscosity Forecast by BP Neural Network Materials Science (Medžiagotyra) 21 (4) 2015: pp. 559-562. https://doi.org/10.5755/j01.ms.21.4.9698

16. Jain, R., Mahto, V. Evaluation of Polyacrylamide/claycomposite as a Potential Drilling Fluid Additive in Inhibitive Water Based Drilling Fluid System 
Journal of Petroleum Science and Engineering

2015: pp. $612-621$.

https://doi.org/10.1016/j.petrol.2015.07.009.

17. Slany, M., Jankovic, L., $\quad$ Madejova, J. Structural Characterization of Organo-montmorillonites Prepared from a Series of Primary Alkylamines Salts: Mid-IR and Near-IR Study Applied Clay Science 176 2019: pp. 11-20. https://doi.org/10.1016/j.clay.2019.04.016

18. Madejová, J., Sekeráková, L., Bizovská, V., Slaný, M., Jankovič, M. Near-Infrared Spectroscopy as an Effective Tool for Monitoring the Conformation of Alkylammonium Surfactants in Montmorillonite Interlayers Vibrational Spectrocopy 84 2016: pp. 44-52.

http://dx.doi.org/10.1016/j.vibspec.2016.02.010

19. Huang, Y., Deng, J., Wang, W.Q., Feng, Q.M., Xu, Z.H. Preliminary Investigation of Pozzolanic Properties of Calcined Waste Kaolin Materials Science (Medžiagotyra) 24 (2) 2018: pp. 177-184. https://doi.org/10.5755/j01.ms.24.2.18192.

20. Salles, F., Douillard, J.M., Bildstein, O., Gaudin, C., Prelot, B., Zajac, J., Damme, H.V. Driving Force for the Hydration of the Swelling Clays: Case of Montmorillonites Saturated with Alkaline-earth Cations Journal of Colloid and Interface Science 395 2013: pp. 269-276. https://doi.org/10.1016/j.jcis.2012.12.050.
21. Boek, E.S., Coveney, P.V., Skipper, N.T. Monte Carlo Molecular Modeling Studies of Hydrated Li-, Na-,and KSmectites: Understanding the Role of Potassium as a Clay Swelling Inhibitor Journal of the American Chemical Society 117 1995: pp. $12608-12617$. https://pubs.acs.org/doi/10.1021/ja00155a025.

22. Caglar, B., Çırak, Ç., Tabak, A., Afsin, B., Eren, E. Covalent Grafting of Pyridine-2-Methanol into Kaolinite Layers Journal of Molecular Liquids 1032 2013: pp. $12-22$. https://doi.org/10.1016/j.molstruc.2012.08.004.

23. Du, W.C., Pu, X.L., Sun, J.S., Luo, X., Zhang, Y.N., Li, L. Synthesis and Evaluation of a Novel Monomeric Amine as Sodium Montmorillonite Swelling Inhibitor Adsorption Science \& Technology $36(1-2)$ 2018: pp. 655-668. https://doi.org/10.1177/0263617417713851.

24. Žukas, T., Jankauskaitė, V., Žukienė, K., Baltušnikas, A. The Influence of Nanofillers on the Mechanical Properties of Carbon Fibre Reinforced Methyl Methacrylate Composite Materials Science (Medžiagotyra) 18 (3) 2012: pp. 250-255. https://doi.org/10.5755/j01.ms.18.3.2434

25. Pérez, A., Montes, M., Molina, R., Moreno, S. Modified Clays as Catalysts for the Catalytic Oxidation of Ethanol Applied Clay Science 95 2014: pp. 18-24. https://doi.org/10.1016/j.clay.2014.02.029. 